\title{
Milliliter per Gram per Hour
}

National Cancer Institute

\section{Source}

National Cancer Institute. Milliliter per Gram per Hour. NCI Thesaurus. Code C73756.

A dose calculation unit expressed in milliliter(s) per gram per period of time equal to sixty minutes. 